\title{
SWARA Tabanlı CODAS Yöntemi İle Kargo Şirketi Seçimi
}

\author{
Alptekin ULUTAŞ ${ }^{1}$
}

\section{Öz}

Kargo taşımacılık hizmetleri, lojistiğin temel faaliyetlerinden birisidir. Kargo firmalarının müşteriye sundukları hizmetin kalitesi kargo firmasından kargo firmasına değişmektedir. Ayrıca bazen müşterilerin gönderdiği kargolar tam zamanında gönderim adresine ulaşamamakta ve bazı zamanlarda da müşterilerin kargoları kaybolma ve taşıma sırasında hasar görme gibi durumlarla karşılaşabilmektedir. Bunun önüne geçmek için müşteri iyi bir kargo firması ile kargosunu göndermesi gerekmektedir. Kargo firmasının seçiminde, kargo firmasına yapılan ödeme, kargo firmasına güven ve kargo firmasının sunduğu hizmetlerin kalitesi vb. birçok faktör göz önünde bulundurulması gerekmektedir. Bu sebeplerden dolayı ÇKKV (çok kriterli karar verme) yöntemleri kullanılarak en iyi kargo firması seçimi yapılabilir. $\mathrm{Bu}$ çalışma üç araştırma boşluğunu doldurmaya çalışmaktadır. İlk olarak ÇKKV yöntemlerini kullanarak kargo hizmetinin değerlendirilmesi ile ilgili çalışma literatürde az sayıda bulunmaktadır. İkinci olarak SWARA ve CODAS yöntemlerinin birlikte kullanımı ile ilgili çalışma sayısı literatürde az bulunmaktadır. Üçüncü olarak CODAS yöntemi ile ilgili Türkçe çalışma sayısı literatürde az sayıda bulunmaktadır. Bu çalışma yukarıdaki üç araştırma boşluğunu doldurmak için SWARA ve CODAS yöntemlerinden oluşan bir birleşik ÇKKV modeli önermiştir. Gelecek çalışmalar, bu çalışmada önerilen birleşik yöntemi farklı ÇKKV problemlerini örneğin bilgisayar seçimi, tedarikçi seçimi ve üçüncü parti lojistik firmalarının seçimi vb. çözmek için kullanabilirler.

\section{Anabtar Kelimeler: SWARA, CODAS, Kargo}

\section{SWARA Based CODAS Method for Cargo Company Selection}

\begin{abstract}
Cargo transportation services are one of the basic activities of logistics. The quality of the services offered by the cargo companies to the customer varies from the cargo company to the cargo company. In addition, sometimes the cargos sent by the customers cannot reach on time shipping address and at some times the customers' cargoes may be lost and damaged during transportation. To avoid this, the customer has to send his/her cargo with a good cargo company. In the selection of the cargo company, many factors, such as payment to the cargo company, trust in the cargo company and the quality of the services offered by the cargo company, etc. are needed to be considered. Therefore, it is possible to choose the best cargo company by using MCDM (multi-criteria decision-making) methods. This study tries to fill three research gaps. Firstly, there are few studies in the literature regarding the evaluation of cargo services by using MCDM methods. Secondly, the number of studies related to the use of SWARA (Step-wise weight assessment ratio analysis) and CODAS (Combinative distance-based assessment) methods together are few in the literature. Third, the number of Turkish studies related to CODAS method is few in literature. This study proposed a combined model of MCDM consisting of SWARA and CODAS methods to fill the above three research gaps. Future studies can use the combined method proposed in this study to solve different MCDM problems, such as the selection of computer, supplier selection and, the selection of third-party logistics companies, etc.
\end{abstract}

Key Words: SWARA, CODAS, Cargo

Atıf İçin / Please Cite As:

Ulutaş, A. (2020). SWARA tabanlı CODAS yöntemi ile kargo şirketi seçimi. Manas Sosyal Araştırmalar Dergisi, 9(3), 1640-1647.

Geliş Tarihi / Received Date: 30.04.2019

Kabul Tarihi / Accepted Date: 25.06.2020

\footnotetext{
${ }^{1}$ Dr. Öğr. Üyesi - Sivas Cumhuriyet Üniversitesi İ̈BF Uluslararası Ticaret ve Lojistik Bölümü, aulutas@cumhuriyet.edu.tr ORCID: 0000-0002-8130-1301
} 


\section{Giriş}

Tedarik zincirinin bașından sonuna kadar olan bilgi ve malzemenin istenilen șekilde ve zamanda istenilen yere götürülmesi işlemlerinin tümüne lojistik denir. Kargo taşımacıllk hizmetleri, lojistiğin temel faaliyetlerinden birisi olarak nitelendirilir. Kargo taşımacıllı̆̆, bir postanın ya da yükün bir yer veya konumdan başka bir yer veya konuma iletilmesi ile ilgili aktivitelerin tamamını kapsamaktadır. Kargo firmalarının müşteriye sunduklanı hizmetin kalitesi kargo firmasından kargo firmasına değişmektedir. Bazı zamanlarda müşterinin gönderdiği kargolar tam zamanında teslim edilemediği gibi bazı zamanlarda da müşterinin kargosu kaybolma ve taşıma esnasında hasar görme gibi durumlarla karşılaşabilmektedir. Bu gibi durumların önüne geçilmesi için müşterinin iyi bir kargo firmasını tercih etmesi gerekmektedir. Kargo firmasının seçiminde, kargo firmasına yapılan ödeme, kargo firmasına güven ve kargo firmasının sunduğu hizmetlerin kalitesi vb. birçok faktör göz önünde bulundurulması gerekmektedir. Çok sayıda ve umumiyetle birbirleriyle çelişen kriterlerin olduğu hâllerde soruna çözüm oluşturabilmek için, "Çok Kriterli Karar Verme (ÇKKV)" yöntemlerinden faydalanılmaktadır (Bülbül ve Köse, 2016). Literatürde birçok kez ÇKKV yöntemleri ile birçok farklı ÇKKV problemlerine başarılı çözümler oluşturulmuştur. Ancak kargo firmaları ile ilgili karar verme problemlerinin çözümünde ÇKKV yöntemlerinin kullanımı literatürde az sayıda çalışmada bulunmaktadır. Tablo 1, bu çalışmaları özetlemiştir.

Tablo 1. Literatür Taramast

\begin{tabular}{|c|c|}
\hline Yazarlar & Çalışma Özeti \\
\hline Tu vd. (2010) & $\begin{array}{l}\text { Bir havaalanı kargo lojistik merkezi için yer seçimi problemi için Kalite Fonksiyon Göçerimi, } \\
\text { AHS (analitik hiyerarşi süreci) ve } 0-1 \text { hedef programlamayı içeren bir model önerilmiştir. }\end{array}$ \\
\hline Kundakcı vd. (2014) & $\begin{array}{l}\text { AAS (analitik ağ süreci) ve DEMATEL yöntemlerini birlikte kullanarak bir tekstil firması } \\
\text { için en iyi kargo taşımacilı şirketi belirlenmiştir. }\end{array}$ \\
\hline Mirzaei vd. (2015) & $\begin{array}{l}\text { İran'daki Ghaen şehri kargo terminali için en iyi konum aralıklı bulanık AHS yöntemi ile } \\
\text { tespit edilmiştir. }\end{array}$ \\
\hline Göleç vd. (2016) & $\begin{array}{l}\text { En iyi askeri kargo uçağ } \text { AHS, ELECTRE, SAW ve TOPSIS metotları kullanılarak tespit } \\
\text { edilmiştir. }\end{array}$ \\
\hline Tüysüz ve Şimşek (2017) & $\begin{array}{l}\text { Bir kargo firmasının şubelerinin performansını etkileyen faktörleri tespit etmek ve bu } \\
\text { faktörlerin önem seviyelerini hesaplamak için sezgisel AHS yöntemi kullanılmıștır. }\end{array}$ \\
\hline Özdemir ve Güneroğlu (2018) & $\begin{array}{l}\text { Kuru yük gemisi şirketleri için kargo tipi seçimi sorunu, bulanık AHS ve bulanık TOPSIS } \\
\text { yöntemleri kullanılarak analiz edilmiştir. }\end{array}$ \\
\hline Ayrim vd. (2018) & $\begin{array}{l}\text { Dört büyük kargo taşımacıllı şirketinin performanslarını analiz etmek için stokastik } \\
\text { COPRAS yöntemi kullanılmıştır. }\end{array}$ \\
\hline Asoğlu ve Eren (2018) & $\begin{array}{l}\text { Bir firma için kargo şirketi belirlemek için AHS, TOPSIS ve PROMETHEE yöntemleri } \\
\text { kullanılmıstır. }\end{array}$ \\
\hline Ulutaş ve Karaköy (2019) & $\begin{array}{l}\text { CRITIC ve ROV yöntemleri birlikte kullanılarak bir kargo firmasının yıllara göre } \\
\text { performansları ölçülmüştür. }\end{array}$ \\
\hline
\end{tabular}

Tablo 1'den de anlaşlacağı üzere ÇKKV yöntemlerinin kullanımı ile yapılan çalışma sayısı literatürde çok az sayıdadır. Bundan dolayı bu çalışmada SWARA ve CODAS yöntemleri kullanılmıştır. SWARA yöntemi daha önce birçok ÇKKV probleminin çözümünde literatürde kullanılmıştır. Bu problemlerden bazıları şunlardır; personel seçimi (Keršulienè ve Turskis, 2011; Karabašević vd., 2016; Dahooie vd., 2018), havalandırma alternatifinin seçimi (Zolfani vd., 2013), tedarikçi seçimi (Alimardani vd., 2013; Adalı ve Işık, 2017; Toklu vd., 2018), makine parçası seçimi (Aghdaie vd., 2013) ve fitness merkezlerinin performans değerlendirmesi (Çakır, 2018).

CODAS yöntemi yeni geliştirilmesine rağmen birçok çalşmada ÇKKV problemlerinin çözümünde kullanılmıştır. Bunlardan bazıları şu şekildedir; pazar bölümlerinin değerlendirilmesi (Keshavarz Ghorabaee vd., 2017), tedarikçi seçimi (Badi vd., 2018; Bolturk, 2018), güç üretim teknolojisi seçimi (Pamučar vd., 2018), personel seçimi (Tuş ve Adal, 2018; Yalçın ve Pehlivan, 2019), bakım stratejilerinin değerlendirilmesi (Panchal vd., 2017) ve malzeme taşıma ekipmanı seçimi (Mathew ve Sahu, 2018).

ÇKKV yöntemleri kullanarak kargo hizmetinin değerlendirilmesi ile ilgili çalışma literatürde az sayıda bulunmaktadır. Bu sebepten dolayı bu çalışmada SWARA ve CODAS yöntemlerinden oluşan bir birleşik ÇKKV modeli kullanılarak bir işletme için en iyi kargo firması belirlenmiştir. Bu iki yöntemin birlikte kullanımı ile ilgili çalışma sayısı literatürde az olduğu için bu çalışma bu araştırma boşluğunu da doldurmaktadır. Ayrıca CODAS yöntemi ile ilgili Türkçe çalışma sayısı literatürde az sayıda bulunmaktadır (Tuş ve Adalı, 2018; Bakır ve Alptekin, 2018; Ayyıldız ve Yalçın, 2018; Ayçin ve Arsu, 2019). Bu araştırma boşlukları da bu çalışmada doldurulacaktır. 


\section{Yöntem}

$\mathrm{Bu}$ çalısmada SWARA ve CODAS yöntemleri kullanılmıştır. SWARA yöntemi kriterlerin ağırlıklarının tespiti için kullanılırken, CODAS yöntemi alternatiflerin sıralanması için kullanılmıştır.

\section{SWARA Yöntemi}

SWARA yöntemi, Keršuliene vd. (2010) tarafından geliştirilmiştir. SWARA yönteminin adımları kısaca şu şekilde özetlenebilir (Stanujkic vd., 2015):

Adım 1: Uzmanlar, kriterleri tahmini önem seviyelerine göre en önemliden en önemsize kadar sıralar.

Adım 2: İkinci kriterden başlanarak, $j-1$. kriter ile $j$. kriter kıyaslanır. $j-1$. kriterin $j$. kritere göre ne kadar önemli olduğu bulunur. Bu bulunan değere $\left(s_{j}\right)$, Keršuliene vd. (2010) tarafindan "ortalama değerin karşılaştırmalı önemi" adı verilmiştir. Bu değerin tespitinde uzmanlar, 0,05 ve katlarını kullanmışlardır.

Adım 3: Eşitlik 1 ile $k_{j}$ katsayısı hesaplanır.

$$
k_{j}=\left\{\begin{array}{cc}
1 & j=1 \\
s_{j}+1 & j>1
\end{array}\right.
$$

Adım 4: Eşitlik 2 ile yeniden hesaplanmış ağırlık $\left(q_{j}\right)$ değeri hesaplanır.

$$
q_{j}=\left\{\begin{array}{cc}
1 & j=1 \\
\frac{q_{j-1}}{k_{j}} & j>1
\end{array}\right.
$$

Adım 5: Eşitlik 3 ile her bir kriterin ağırlığı $\left(w_{j}\right)$ bulunur.

$$
w_{j}=\frac{q_{j}}{\sum_{j=1}^{n} q_{j}}
$$

\section{CODAS Yöntemi}

İki farklı uzaklık ölçümünden yola çıkarak sonuca ulaşan CODAS yöntemi, Keshavarz Ghorabaee vd. (2016) tarafindan literatüre tanıtılmıştır. CODAS yöntemi aşağıda özetlenmiştir (Keshavarz Ghorabaee vd., 2016).

Adım 1: CODAS yönteminin ilk adımı olarak, alternatiflerden ve kriterlerden oluşan bir karar matrisi oluşturulur. Aşağıdaki eşitlik karar matrisini göstermektedir.

$$
T=\left[t_{i j}\right]_{m \times n}=\left[\begin{array}{cccc}
t_{11} & t_{12} & \cdots & t_{1 n} \\
t_{21} & t_{22} & \cdots & t_{2 n} \\
\vdots & \vdots & \vdots & \vdots \\
t_{m 1} & t_{m 2} & \cdots & t_{m n}
\end{array}\right]
$$

Adım 2: Karar matrisindeki değerler, eşitlik 5 (faydalı kriterler) ve eşitlik 6 (maliyet kriterleri) yardımı ile normalize edilir.

$$
\begin{aligned}
t_{i j}^{\prime} & =\frac{t_{i j}}{\operatorname{mak}\left(t_{i j}\right)} \\
t_{i j}^{\prime} & =\frac{\min \left(t_{i j}\right)}{t_{i j}}
\end{aligned}
$$

Adım 3: Normalize edilmiş değerler, SWARA yöntemi kullanımı ile elde edilen kriter ağırlıkları çarpılır ve böylece ağırlıklı normalize karar matrisi elde edilir. Aşağıdaki eşitlik bu işlemi göstermektedir.

$$
t_{i j}^{*}=t_{i j}^{\prime} w_{j}
$$

Adım 4: Her bir kriter için negatif ideal çözüm eşitlik 8 ile hesaplanır.

$$
n s_{j}=\min \left(t_{i j}^{*}\right)
$$

Adım 5: Alternatiflerin negatif ideal çözüme olan Öklid ve Taxicab uzaklıkları aşağıdaki eşitlikler yardımı ile ölçülür. 


$$
\begin{aligned}
P_{i} & =\sqrt{\sum_{j=1}^{n}\left(t_{i j}^{*}-n s_{j}\right)^{2}} \\
Q_{i} & =\sum_{j=1}^{n}\left|t_{i j}^{*}-n s_{j}\right|
\end{aligned}
$$

Adım 6: Aşağıdaki eşitlikler yardımı ile göreceli değerlendirme matrisi hesaplanır.

$$
\begin{gathered}
R_{\alpha}=\left[u_{i b}\right]_{m \times m} \\
u_{i b}=\left(P_{i}-P_{b}\right)+\left(\omega\left(P_{i}-P_{b}\right) \times\left(Q_{i}-Q_{b}\right)\right)
\end{gathered}
$$

Eşitlik 12'de gösterilen, $\omega$ bir eşik fonksiyonudur. Bu fonksiyon iki alternatifin arasındaki Öklid uzaklıklarının eşitliklerini belirlemek için kullanılır ve şu şekilde ifade edilir:

$$
\omega(x)= \begin{cases}0, & |x|<\tau \\ 1, & |x| \geq \tau\end{cases}
$$

Eşitlik 13’te bulunan $\tau$ değeri eşik parametresidir. Bu değer karar vericiler tarafından 0,01-0,05 arasında bir değer olarak ayarlanır. Bu değer bu çalışmada 0,02 alınmıştır.

Adım 7: Son performans skor $\left(A S_{i}\right)$ her bir alternatif için aşağıdaki eşitlik ile hesaplanır. En yüksek performans skoruna sahip alternatif en iyi alternatif olarak belirlenir.

$$
A S_{i}=\sum_{b=1}^{n} u_{i b}
$$

\section{Uygulama}

Türkiye'nin Doğu Anadolu bölgesindeki bir ilde yer alan bir işletme, ürünlerini diğer illerdeki müşterilerine ulaştırmak için bir kargo firması ile çalışmak istemektedir. İşletme uzun yıllardır gida sektöründe yer almaktadır. Değerlendirmeye başlamak için işletmenin yöneticilerinden oluşan bir uzman ekip oluşturuldu. $\mathrm{Bu}$ uzman ekipten kargo firması seçiminde kullanılmak üzere kriterler belirlemeleri istendi. Aşağıda ekip tarafından belirlenen kriterler sıralanmıştır.

- Zamanında Teslim (ZT): Gönderinin, müşterinin eline söz verilen tarihte geçmesi.

- Personelin Davranışları (PD): Kargo firmasında çalışan personelin gönderimde bulunacak işletme çalışanlarına nazik ve saygıılı bir şekilde yaklaşması ve davranışta bulunması.

- Firmanın Takip Sistemi (FTS): Kargo takip sistemi ile müşteriye kargosunu anlık olarak takip etme imkânı sunması.

- Teminat (T): Kargo faaliyetleri sırasında oluşabilecek hasar ve zararlar için teminat verilmesi.

- Promosyon (P): Fiyatlandırma yapilırken, fiyatta indirime gidilmesi, bazı ürün gönderimlerinde ücret alınmaması, daha fazla ürün gönderiminde fiyatların sabitlenmesi ve benzeri promosyonlarin yapilması.

- Gönderim ücreti (GÜ): Kargo gönderiminde ödenen gönderim ücretinin makul miktarda olması.

SWARA ve CODAS yöntemlerindeki değerlendirmelerde uzman ekip ortak karar verdi. CODAS yönteminde kargo firmalarına uzman ekip faydalı kriterler için 1 (en kötü) - 9 (en iyi), maliyet kriterleri için ise 1 (en iyi) - 9 (en kötü) arası performans puanları verdiler. SWARA yönteminin sonuçları Tablo 2'de gösterilmiştir.

Tablo 2. SWARA Sonuclar

\begin{tabular}{ccccccc}
\hline Kriterler & $\begin{array}{c}\text { Önem } \\
\text { Siralamas1 }\end{array}$ & $\begin{array}{c}\text { Kriterlerin } \\
\text { Siralamasi }\end{array}$ & $\boldsymbol{s}_{\boldsymbol{j}}$ & $\boldsymbol{k}_{\boldsymbol{j}}$ & $\boldsymbol{q}_{\boldsymbol{j}}$ & $\boldsymbol{w}_{\boldsymbol{j}}$ \\
\hline ZT & 1 & ZT & & 1 & 1 & 0,196 \\
PD & 6 & GÜ & 0,05 & 1,05 & 0,952 & 0,186 \\
FTS & 4 & T & 0,1 & 1,1 & 0,865 & 0,169 \\
T & 3 & FTS & 0,05 & 1,05 & 0,824 & 0,161 \\
P & 5 & P & 0,05 & 1,05 & 0,785 & 0,154 \\
GÜ & 2 & PD & 0,15 & 1,15 & 0,683 & 0,134 \\
\hline
\end{tabular}

Tablo 2'den de görüleceği üzere, kriterler ağırlıklarına göre şöyle sıralanmaktadır; ZT> GÜ> T> FTS $>$ P $>$ PD. SWARA yöntemi ile elde edilen kriter ağırlıkları, CODAS yöntemine aktarılır. Alternatiflerin kriterlere göre değerlendirilmesinin yapıldığı karar matrisi Tablo 3’te gösterilmiştir. 
Tablo 3. Karar Matrisi

\begin{tabular}{ccccccc}
\hline Kriterler & GT & T & FTS & P & PD \\
\hline Alternatifler & & & 7 & 8 & 6 & 7 \\
KF1 & 9 & 2 & 7 & 9 & 7 & 6 \\
KF3 & 9 & 3 & 7 & 6 & 6 & 6 \\
KF4 & 8 & 2 & 7 & 6 & 6 & 6 \\
KF5 & 7 & 3 & 8 & 6 & 6 & 6 \\
KF6 & 9 & 4 & 7 & 6 & 6 & 7 \\
\hline
\end{tabular}

Eşitlikler 5 ve 6 yardımı ile karar matrisi normalize edilir. Tablo 4 normalize karar matrisini sunmaktadır.

Tablo 4. Normalize Karar Matrisi

\begin{tabular}{|c|c|c|c|c|c|c|}
\hline & $\mathrm{ZT}$ & GÜ & $\mathrm{T}$ & FTS & $\mathrm{P}$ & PD \\
\hline \multicolumn{7}{|l|}{ Alternatifler } \\
\hline $\mathrm{KF} 1$ & 1 & 1 & 0,875 & 0,889 & 0,857 & 1 \\
\hline KF2 & 1 & 0,667 & 0,875 & 1 & 1 & 0,857 \\
\hline KF3 & 0,889 & 1 & 1 & 0,778 & 0,857 & 0,714 \\
\hline KF4 & 0,778 & 0,667 & 0,875 & 0,667 & 0,857 & 0,857 \\
\hline KF5 & 1 & 0,5 & 1 & 1 & 1 & 0,857 \\
\hline KF6 & 0,778 & 0,5 & 0,875 & 0,667 & 0,857 & 0,857 \\
\hline
\end{tabular}

Eşitlik 7 ve 8 kullanılarak sırasıyla ağırlıklı normalize değerler ve negatif ideal çözümler bulunur. Tablo 5, ağırlıklı normalize değerleri ve negatif ideal çözümleri göstermektedir.

Tablo 5. Ağırlıkl Normalize Karar Matrisi

\begin{tabular}{|c|c|c|c|c|c|c|}
\hline & $\mathrm{ZT}$ & GÜ & $\mathrm{T}$ & FTS & $\mathrm{P}$ & PD \\
\hline \multicolumn{7}{|l|}{ Alternatifler } \\
\hline KF1 & 0,196 & 0,186 & 0,148 & 0,143 & 0,132 & 0,134 \\
\hline KF2 & 0,196 & 0,124 & 0,148 & 0,161 & 0,154 & 0,115 \\
\hline KF3 & 0,174 & 0,186 & 0,169 & 0,125 & 0,132 & 0,096 \\
\hline KF4 & 0,152 & 0,124 & 0,148 & 0,107 & 0,132 & 0,115 \\
\hline KF5 & 0,196 & 0,093 & 0,169 & 0,161 & 0,154 & 0,115 \\
\hline KF6 & 0,152 & 0,093 & 0,148 & 0,107 & 0,132 & 0,115 \\
\hline$n s_{j}$ & 0,152 & 0,093 & 0,148 & 0,107 & 0,132 & 0,096 \\
\hline
\end{tabular}

Bu matrise eşitlikler 9 ve 10 kullanılarak, Öklid ve Taxicab uzaklıkları hesaplanır. Bu uzaklıklar hesaplandiktan sonra eşitlik 12 vasıtasıyla göreceli değerlendirme matrisi hesaplanır. Bu matris bulunduktan sonra son performans skoru $\left(A S_{i}\right)$ her bir kargo firması için eşitlik 14 ile hesaplanır. Tablo 6, göreceli değerlendirme matrisini ve sonuçları göstermektedir.

Tablo 6. Göreceli Değerlendirme Matrisi ve Sonuclar

\begin{tabular}{ccccccccc} 
& & & & & \\
Klternatifler & & & & & & & \\
KF1 & KF2 & KF3 & KF4 & KF5 & KFalama \\
\hline KF1 & 0 & 0,074 & 0,016 & 0,24 & 0,088 & 0,288 & 0,706 & 1 \\
KF2 & $-0,074$ & 0 & $-0,017$ & 0,166 & 0,004 & 0,214 & 0,293 & 3 \\
KF3 & $-0,016$ & 0,017 & 0 & 0,167 & 0,015 & 0,215 & 0,398 & 2 \\
KF4 & $-0,24$ & $-0,166$ & $-0,167$ & 0 & $-0,152$ & 0,017 & $-0,708$ & 5 \\
KF5 & $-0,088$ & $-0,004$ & $-0,015$ & 0,152 & 0 & 0,2 & 0,245 & 4 \\
KF6 & $-0,288$ & $-0,214$ & $-0,215$ & $-0,017$ & $-0,2$ & 0 & $-0,934$ & 6 \\
\hline
\end{tabular}

Tablo 6'ya göre KF1 kargo firması 6 kargo firması arasında en iyi kargo firması olarak belirlenmiştir. 


\section{Sonuçlar}

Lojistiğin temel faaliyetlerinden biri kargo taşımacıllk hizmetleridir. Bu hizmeti sağlayan kargo firmalarının hizmet kalitesi kargo firmasından kargo firmasına değişkenlik göstermektedir. Bazı durumlarda müșteri kargosu ile ilgili sorunlarla karșı karșıya kalmaktadır. Örneğin, bazen müșteriye ait kargolar tam zamanında ulaştırılamadığı gibi bazen de müşteriye ait kargolar kaybolabilmekte veya sevkiyat sırasında hasar görebilmektedir. Bunun gibi kötü durumlar ile karşılaşmamak için müşteriler, kargolarını en iyi kargo firmasını kullanarak iletmeleri gerekmektedir. En iyi kargo firmasının belirlenmesinde, kargo firmasına yapılan ödeme, kargo firmasına duyulan güven ve kargo firmasının sağladığı hizmetlerin kalitesi vb. birçok faktör hesaba katılması gerekmektedir. Bu sebeplerden dolayı ÇKKV yöntemleri kullanılarak en iyi kargo firması seçimi yapılabilir. Bu çalışma üç araştırma boşluğunu doldurmaya çalışmıştır. İlk olarak ÇKKV yöntemleri kullanılarak kargo hizmetinin değerlendirilmesi ile ilgili çalışma literatürde az sayıda bulunmaktadır. İkinci olarak SWARA ve CODAS yöntemlerinin birlikte kullanımı ile ilgili çalışma sayısı literatürde az bulunmaktadır. Üçüncü olarak CODAS yöntemi ile ilgili Türkçe çalışma sayısı literatürde az sayıda bulunmaktadır. Bu çalışma yukarıdaki üç araştırma boşluğunu doldurmak için SWARA ve CODAS yöntemlerinden oluşan bir birleşik ÇKKV modeli önermiştir. Bu birleşik yöntemin uygulaması Türkiye'nin Doğu Anadolu bölgesindeki bir ilde yer alan bir işletmede yapılmıştır. Bu uygulamada altı kargo firması alternatifi belirlenmiş ve bunların içinden en iyi performansa sahip KF1 firması en iyi kargo firması olarak tespit edilmiştir. Gelecek çalışmalar, bu çalışmada önerilen birleşik ÇKKV yöntemini farklı ÇKKV problemlerinin çözümünde örneğin bilgisayar seçimi, tedarikçi seçimi ve üçüncü parti lojistik firmalarının seçiminde kullanabilirler.

\section{Etik Beyan}

"SWARA Tabank CODAS Yöntemi İle Kargo Şirketi Seçimi” başlıklı çalışmanın yazım sürecinde bilimsel, etik ve alıntı kurallarına uyulmuş; toplanan veriler üzerinde herhangi bir tahrifat yapılmamış ve bu çalışma herhangi başka bir akademik yayın ortamına değerlendirme için gönderilmemiştir.

\section{Kaynakça}

Adalı, E. A., \& Işık, A. T. (2017). Bir Tedarikçi Seçim Problemi için SWARA ve WASPAS Yöntemlerine Dayanan Karar Verme Yaklaşımı. International Review of Economics and Management, 5(4), 56-77.

Aghdaie, M. H.,Hashemkhani Zolfani, S. H., \& Zavadskas, E. K. (2013). Decision making in machine tool selection: An integrated approach with SWARA and COPRAS-G methods. Engineering Economics, 24(1), 5-17.

Alimardani, M., Zolfani, S. H., Aghdaie, M. H., \& Tamošaitiené, J. (2013). A novel hybrid SWARA and VIKOR methodology for supplier selection in an agile environment. Technological and Economic Development of Economy, 19(3), 533-548.

Asoğlu, İ., \& Eren, T. (2018). AHP, TOPSIS, PROMETHEE Yöntemleri ile Bir İşletme için Kargo Şirketi Seçimi. Yalova Sosyal Bilimler Dergisi, 8(16), 102-122.

Ayçin, E., \& Arsu, T. (2019). CODAS ve Entropi Yöntemleri İle Yenilenebilir Enerji Kaynaklarının Düzey 1 Bölgelerine Göre İncelenmesi. Avrasya Uluslararası Arasttrmalar Dergisi, 7(18), 425-447.

Ayrim, Y., Atalay, K. D., \& Can, G. F. (2018). A New Stochastic MCDM Approach Based on COPRAS. International Journal of Information Technology \& Decision Making, 17(03), 857-882.

Ayylldı, E., \& Yalçın, S. (2018). Türkiye'de Yer Alan Lojistik Dostu Şehirlerin Bütünleşik Entropi-CODAS Kullanilarak Belirlenmesi. Uludağ University Journal of The Faculty of Engineering, 23(4), 127-140.

Badi, I., Abdulshahed, A. M., \& Shetwan, A. (2018). A case study of supplier selection for a steelmaking company in Libya by using the Combinative Distance-based ASsessment (CODAS) model. Decision Making: Applications in Management and Engineering, 1(1), 1-12.

Bakır, M., \& Alptekin, N. (2018). Hizmet Kalitesi Ölçümüne Yeni Bir Yaklaşım: CODAS Yöntemi İle Havayolu İşletmeleri Üzerine Bir Uygulama. Business \& Management Studies: An International Journal, 6(4), 1336-1353.

Bolturk, E. (2018). Pythagorean fuzzy CODAS and its application to supplier selection in a manufacturing firm. Journal of Enterprise Information Management, 31(4), 550-564.

Bülbül, S. E., \& Köse, A. (2016). Türk sigorta sektörünün PROMETHEE yöntemi ile finansal performans analizi. Marmara Üniversitesi İktisadi ve İdari Bilimler Dergisi, 38(1), 187-210.

Çakır, E. (2018). Bütünleşik SWARA ve EDAS yöntemi kullanarak fitness merkezlerinin değerlendirilmesi: Örnek bir uygulama. Hitit Üniversitesi Sosyal Bilimler Enstitïsü Dergisi, 11(3), 1907- 1923.

Dahooie, J. H., Abadi, E. B. J., Vanaki, A. S., \& Firoozfar, H. R. (2018). Competency-based IT personnel selection using a hybrid SWARA and ARAS-G methodology. Human Factors and Ergonomics in Manufacturing \& Service Industries, 28(1), 5-16.

Göleç, A., Gürbüz, F., \& Şenyiğit, E. (2016). Determination of Best Military Cargo Aircraft with Multi-Criteria Decision-Making Techniques. MANAS Journal of Social Studies, 5(5), 87-101. 
Karabašević, D., Stanujkić, D., Urošević, S., \& Maksimović, M. (2016). An approach to personnel selection based on Swara and Waspas methods. Bizinfo (Blace) Journal of Economics, Management and Informatics, 7(1), 1-11.

Keršuliene, V., Zavadskas, E. K., \& Turskis, Z. (2010). Selection of rational dispute resolution method by applying new step-wise weight assessment ratio analysis (SWARA). Journal of business economics and management, 11(2), 243258.

Keršuliené, V., \& Turskis, Z. (2011). Integrated fuzzy multiple criteria decision making model for architect selection. Technological and Economic Development of Economy, 17(4), 645-666.

Keshavarz Ghorabaee, M., Zavadskas, E. K., Turskis, Z., \& Antucheviciene, J. (2016). A New Combinative Distance-Based Assessment (CODAS) Method for Multi-Criteria Decision-Making. Economic Computation \& Economic Cybernetics Studies \& Research, 50(3), 25-44.

Keshavarz Ghorabaee, M., Amiri, M., Zavadskas, E. K., Hooshmand, R., \& Antuchevičiené, J. (2017). Fuzzy extension of the CODAS method for multi-criteria market segment evaluation. Journal of Business Economics and Management, 18(1), 1-19.

Kundakc1, N., Adalı, E. A., \& Işık, A. T. (2014). Combination of DEMATEL and ANP for the cargo shipping company selection problem. International Journal of Engineering Management and Economics, 4(2), 99-116.

Mathew, M., \& Sahu, S. (2018). Comparison of new multi-criteria decision making methods for material handling equipment selection. Management Science Letters, 8(3), 139-150.

Mirzaei, E., Minatour, Y., Bonakdari, H., \& Javadi, A. (2015). Application of interval-valued fuzzy analytic hierarchy process approach in selection cargo terminals, a case study. International Journal of Engineering-Transactions C: Aspects,28(3), 387-395.

Özdemir, Ü., \& Güneroğlu, A. (2018). Cargo type selection procedure using fuzzy AHP and fuzzy TOPSIS techniques:'the case of dry bulk cargo ships'. International Journal of Shipping and Transport Logistics, 10(3), 259-280.

Pamučar, D., Badi, I., Sanja, K., \& Obradović, R. (2018). A novel approach for the selection of power-generation technology using a linguistic neutrosophic CODAS method: A case study in Libya. Energies, $11(9), 2489$.

Panchal, D., Chatterjee, P., Shukla, R. K., Choudhury, T., \& Tamosaitiene, J. (2017). Integrated Fuzzy AHP-CODAS Framework for Maintenance Decision in Urea Fertilizer Industry. Economic Computation \& Economic Cybernetics Studies \& Research, 51(3), 179-196.

Stanujkic, D., Karabasevic, D., \& Zavadskas, E. K. (2015). A framework for the selection of a packaging design based on the SWARA method. Inzinerine Ekonomika-Engineering Economics, 26(2), 181-187.

Toklu, M. C., Çağıll, G., Pazar, E., \& Faydalı, R. (2018). SWARA-WASPAS Metodolojisine Dayalı Tedarikçi Seçimi: Türkiye'de Demir-Çelik Endüstrisi Örneği. Akademik Platform Mühendislik ve Fen Bilimleri Dergisi, 6(3), 113-120.

Tu, C. S., Chang, C. T., Chen, K. K., \& Lu, H. A. (2010). Applying an AHP-QFD conceptual model and zero-one goal programming to requirement-based site selection for an airport cargo logistics center. International journal of information and management sciences, 21(4), 407-30.

Tuş, A., \& Adalı, E. A. (2018). Personnel assessment with CODAS and PSI methods. Alphanumeric Journal, 6(2), 243256.

Tüysüz, F., \& Şimşek, B. (2017). A hesitant fuzzy linguistic term sets-based AHP approach for analyzing the performance evaluation factors: An application to cargo sector. Complex \& Intelligent Systems, 3(3), 167-175.

Ulutaş, A., \& Karaköy, Ç. (2019). CRITIC ve ROV Yöntemleri İle Bir Kargo Firmasının 2011-2017 Yılları Sirasindaki Performansinın Analiz Edilmesi. MANAS Sosyal Araştrrmalar Dergisi, 8(1/1), 229-236.

Yalçın, N., \& Pehlivan, N. Y. (2019). Application of the Fuzzy CODAS Method Based on Fuzzy Envelopes for Hesitant Fuzzy Linguistic Term Sets: A Case Study on a Personnel Selection Problem. Symmetry, 11(4), 493.

Zolfani, S. H., Esfahani, M. H., Bitarafan, M., Zavadskas, E. K., \& Arefi, S. L. (2013). Developing a new hybrid MCDM method for selection of the optimal alternative of mechanical longitudinal ventilation of tunnel pollutants during automobile accidents. Transport, 28(1), 89-96.

\section{EXTENDED ABSTRACT}

The activities, which include transportation, warehousing, and planning, etc., of all of the information and materials in the supply chain from the beginning to the end to the desired location and on time are called logistics. Cargo transportation services are considered as one of the basic activities of logistics. Cargo transportation includes all activities related to the transmission of a mail or cargo from one location or point to another location or point. The quality of the services offered by the cargo companies to the customer varies from the cargo company to the cargo company. At some times, the customer's cargos cannot be delivered on time and in some cases the customer's cargo may be lost and damaged during transportation. In order to avoid such situations, the customer should prefer a good cargo company. In the selection of the cargo company, some factors, such as the payment to the cargo company, trust in the cargo company and the quality of the services offered by the cargo company, etc. are needed to take into account. In cases where there are many and often contradictory criteria, MCDM methods can be helpful to solve this type of problems. There are few studies in the literature on the use of MCDM methods to solve decision-making problems related to cargo companies. Tu et al. (2010) proposed a model that 
includes quality function deployment, AHP (analytic hierarchy process) and zero-one goal programming for the problem of location selection for an airport cargo logistics center. In another study, Kundakc1 et al. (2014) integrated ANP (analytic network process) and DEMATEL to select the cargo shipping company. Mirzaei et al. (2015) proposed fuzzy analytic hierarchy process to determine the ideal location for cargo terminal in Ghaen city in Iran. Göleç et al. (2016) suggested MCDM methods, which are AHP, SAW, TOPSIS, ELECTRE, to identify the best military cargo aircraft. Tüysüz and Şimşek (2017) proposed a hesitant sets based AHP to analyze the factors of performance evaluation for the branches of a cargo company. Özdemir and Güneroğlu (2018) combined fuzzy AHP and fuzzy TOPSIS to solve cargo type selection problem for the dry bulk cargo ships. Ayrim et al. (2018) developed stochastic COPRAS model to select the best cargo firm. Asoğlu and Eren (2018) proposed AHP, TOPSIS and PROMETHEE to select the most appropriate cargo firm for a company. Ulutaş and Karaköy (2019) integrated CRITIC and ROV methods to evaluate the performance of a cargo firm over the years. In this study, an MCDM model including SWARA (Step-wise weight assessment ratio analysis) and CODAS (Combinative distance-based assessment) is proposed to identify the most appropriate cargo company for a Turkish firm. The SWARA method has previously been used in the literature to solve many MCDM problems. Some of these problems are as follows; personnel selection (Keršulienè, \& Turskis, 2011; Karabašević et al., 2016; Dahooie et al., 2018), the selection of ventilation alternative (Zolfani et al., 2013), supplier selection (Alimardani et al., 2013; Adalı, \& Işı1k, 2017; Toklu et al., 2018), machine tool selection (Aghdaie et al., 2013) and performance evaluation of fitness centers (Çakır, 2018). Although CODAS method has been newly developed, it has been used in many studies to solve the problems of MCDM. Some of these are as follows; the evaluation of market segments (Keshavarz Ghorabaee et al., 2017), supplier selection (Badi et al., 2018; Bolturk, 2018), the selection of power-generation technology (Pamučar et al., 2018), personnel selection (Tuş, \& Adalı, 2018; Yalçın, \& Pehlivan, 2019), the evaluation of maintenance strategies (Panchal et al., 2017) and the selection of material handling equipment (Mathew, \& Sahu, 2018). This study attempts to fill three research gaps. First, there are few studies in the literature on the evaluation of cargo services using MCDM methods. Second, the number of studies related to the use of SWARA and CODAS methods together are few in the literature. Third, the number of Turkish studies related to CODAS method is few in the literature (Tuş, \& Adalı, 2018; Bakır, \& Alptekin, 2018; Ayyıldız, \& Yalçın, 2018; Ayçin, \& Arsu, 2019). This study proposed a combined MCDM model including SWARA and CODAS methods to fill three research gaps above-mentioned. The application of this combined method has been made in a business located in a province in Eastern Anatolia in Turkey. In this application, six cargo company alternatives and six criteria (on-time delivery, personnel behaviours in cargo company, cargo tracking system of cargo company, guarantee, promotion and price) have been determined. Among six cargo companies, the KF1 company having the highest score has been determined as the best cargo company. Future studies can use the combined method proposed in this study to solve different MCDM problems, such as the selection of computer, supplier selection and, the selection of third-party logistics companies, etc. 